\title{
MATHEMATICAL MODELING IN VIEW OF PROPERTY PREDICTION OF DD11 STEEL LAMINATED IN LBC LIBERTY GALATI
}

\author{
Marian-Iulian NEACȘU \\ "Dunărea de Jos" University of Galaţi, Romania \\ e-mail: uscaeni@yahoo.com
}

\begin{abstract}
The paper presents a mathematical model for predicting the mechanical properties of hot rolled strips. The realization of this mathematical model relied on statistical measurements of the mechanical properties $\left(R_{m}, R_{p 0,2}\right.$ and $\left.A_{5}\right)$ for the laminated strip in the LBC rolling mill from the Liberty Steel Galati steel plant. To achieve this mathematical model, there has been used the active experiment method.

By means of this mathematical model, significant time and material savings can be made in the process of testing the mechanical properties for hot rolled tape.
\end{abstract}

KEYWORDS: mathematical model, statistical measurements, active experiment, mechanical properties

\section{Introduction}

Located in south-eastern Romania, Liberty Galati is the largest integrated plant in the country and a leader in the manufacture of steel products, with a current production capacity of 2 million tons of steel, with the possibility of increasing it. It is known that the current demand of the hot and cold rolled products market is decreasing, which makes the producers of low carbon rolled steel strips and sheets, to permanently increase the research on the way of elaboration, casting and their processing, thereby strengthening the values of mechanical properties necessary for appropriate machinability with beneficial results on the costs of the finished product.

Modeling in general and mathematical modeling in particular, is a basic tool in the design phase but also in the execution phase as well as in the analysis of the functioning of processes. To determine the optimum in a metallurgical process, mathematical modeling is used with the help of computers by using specialized programs [1].

Development of mathematical models in general and statistical data processing methods, in particular, recorded in a technological process made it possible for the optimal decision to be approached on the one hand as a matter of technical efficiency and on the other hand as a matter of high economic efficiency [2].
In the metallurgical industry, the mathematical model of that process can be used to calculate the optimal conditions for that process, but it can also be used to provide information on the optimal management of metallurgical processes [3].

Mathematical modeling by statistical methods has two important stages of realization:

- the first stage is called a preliminary experiment and has the role of solving the problem of selection of process factors as well as the interactions that may occur;

- the second stage called the experiment on which the operator relies to perform real modeling and statistical analysis of the model [4].

The variation of process factors is assessed in the preliminary experiment by performing a series of determinations based on programs (dispersion analysis, correlation analysis, etc.) which allow the selection of factors that significantly influence and highlight the links between factors and their contribution to the process $[3,5]$.

The paper aims to create a mathematical model for predicting the values of mechanical properties of hot rolled strips in LBC from the Liberty Steel Galati plant.

By using this mathematical model, a saving of time and material will be obtained by not performing the operations of effective mechanical tests to establish the values of the mechanical properties pursued. 


\section{Experimental conditions}

Slabs intended for the rolling process from DD11 quality are heated in propulsion furnaces. Heating is performed in order to transform the polyphasic structure of steel into a single-phase austenite structure and dissolve in its mass the carbides [6].

Three different chemical compositions (EC) for hot-rolled DD11 steel were taken into account: 1-CE $=0.1 \% ; 2-\mathrm{CE}=0.09 \% ; 3-\mathrm{CE}=0.08 \%$.

The experimental data had as parameters besides the chemical composition, the rolling end temperature $\left(\mathrm{T}_{\mathrm{f} 1}=900{ }^{\circ} \mathrm{C}, \mathrm{T}_{\mathrm{f} 2}=870{ }^{\circ} \mathrm{C}, \mathrm{T}_{\mathrm{f} 3}=840{ }^{\circ} \mathrm{C}\right)$ and the winding temperature $\left(\mathrm{T}_{\mathrm{w} 1}=606{ }^{\circ} \mathrm{C}, \mathrm{T}_{\mathrm{w} 2}=600{ }^{\circ} \mathrm{C}, \mathrm{T}_{\mathrm{w} 3}\right.$ $=594{ }^{\circ} \mathrm{C}$ ), hot rolled rolls. The hot rolling of the strips is done in a wide temperature range and is accompanied by phase transformations and structure transformation. The paper presents the elaboration of the equations of the mathematical model with the help of which the mechanical properties of the hot rolled strips in LBC Liberty Galati can be predicted.

Mathematical modeling was performed by the method of active experiment, when statistical methods are used in all stages of experimental research:

- before carrying out the experiment, by establishing the number of experiences and the conditions for their realization;

- during the development of experiments by processing the obtained results;

- after the end of the experiment through conclusions regarding the realization of future experiences. The programming of the experiment involves:

- establishing the necessary and sufficient number of experiences and the conditions for their realization;

- determining by statistical methods the regression equation, which represents with a certain degree of approximation, calculable, the process model;

- determining the conditions for achieving the optimal value of the process performance (parameter to be optimized).

\section{Experimental results}

In this paper we have made the mathematical model (regression equation) of the hot rolling process for steel slabs brand DD11, by statistical methods, namely regression analysis by active experiment. The equations of the elaborated mathematical model are of the form: $Y=f\left(x_{1}, x_{2}, x_{3}\right)$. We considered as main influencing factors (independent variables of the process of making hot rolled strips) the following technological processing parameters:

$\mathrm{x}_{1}$ - carbon equivalent $-\mathrm{C}_{\mathrm{E}},[\%]$;

$\mathrm{x}_{2}$ - rolling end temperature $-\mathrm{T}_{\mathrm{f}},\left[{ }^{\circ} \mathrm{C}\right]$;

$\mathrm{x}_{3}$ - winding temperature $-\mathrm{T}_{\mathrm{w}},\left[{ }^{\circ} \mathrm{C}\right]$.

Dependent variables (parameters to be optimized):

$\mathrm{Y}_{1}$ - breaking strength, $\mathrm{R}_{\mathrm{m}}$, [MPa];

$\mathrm{Y}_{2}$ - flow limit, $\mathrm{R}_{\mathrm{p} 02}[\mathrm{MPa}]$

$\mathrm{Y}_{3}$ - specific elongation at break, $\mathrm{A}_{5},[\%]$;

In order to code the experiment, the following notations and symbols were used: $\mathrm{x}_{1}, \mathrm{x}_{2}, \mathrm{x}_{3}$ - the independent variables (process parameters) and $\mathrm{Y}_{1}$, $\mathrm{Y}_{2}, \mathrm{Y}_{3}$ - the dependent variables of the process.

There are the following links between natural and coded values of factors $\mathrm{x}_{\mathrm{i}}$ :

$$
x_{1}=\frac{C_{E}-C_{E 0}}{\Delta C_{E}}, x_{2}=\frac{T_{f}-T_{f 0}}{\Delta T_{f}}, x_{3}=\frac{T_{1}-T_{\hat{1}}}{\Delta T_{W}}
$$

where: $\mathrm{C}_{\mathrm{E}}$-carbon equivalent, $\% ; \mathrm{C}_{\mathrm{E} 0 \text {-carbon }}$ equivalent, base value, $\% ; \Delta \mathrm{C}_{\mathrm{E}}$-variation of $\mathrm{C}_{\mathrm{E}}$ between upper and lower level and between basic and lower level; $\mathrm{T}_{\mathrm{f}}$ - end rolling temperature, ${ }^{\circ} \mathrm{C} ; \mathrm{T}_{\mathrm{f} 0}$ - end rolling temperature at the base level, ${ }^{\circ} \mathrm{C} ; \Delta \mathrm{T}_{\mathrm{f}}-$ variation of $\mathrm{T}_{\mathrm{sf}}$ between the upper level and the basic level and between the basic level and the lower level, ${ }^{\circ} \mathrm{C} ; \mathrm{T}$ - temperature end of rolling, ${ }^{\circ} \mathrm{C} ; \mathrm{T}_{\mathrm{w} 0}$ - end rolling temperature at the base level, ${ }^{\circ} \mathrm{C} ; \Delta \mathrm{T}_{\mathrm{w}}-$ variation of $\mathrm{T}_{\hat{1}}$ between the upper level and the basic level and between the basic level and the lower level, ${ }^{\circ} \mathrm{C} ; \mathrm{Y}_{\mathrm{i}}$ values are expressed in natural units.

Since the influence of the three factors on the performance of the process (Y) is studied, a complete factorial experiment of the type $2^{3}$ has been achieved [2].

Extended matrix of the complete factorial experiment $2^{3}$

\begin{tabular}{|c|c|c|c|c|c|c|c|c|c|c|}
\hline Nr. exp. & $\mathbf{X}_{\mathbf{0}}$ & $\mathbf{X}_{\mathbf{1}}$ & $\mathbf{X}_{\mathbf{2}}$ & $\mathbf{X}_{\mathbf{3}}$ & $\mathbf{X}_{\mathbf{1}} \mathbf{X}_{\mathbf{2}}$ & $\mathbf{X}_{\mathbf{1}} \mathbf{X}_{\mathbf{3}}$ & $\mathbf{X}_{\mathbf{2}} \mathbf{X}_{\mathbf{3}}$ & $\mathbf{Y}_{\mathbf{1}}$ & $\mathbf{Y}_{\mathbf{2}}$ & $\mathbf{Y}_{\mathbf{3}}$ \\
\hline 1 & +1 & +1 & +1 & +1 & +1 & +1 & +1 & 382 & 306 & 29 \\
\hline 2 & +1 & -1 & +1 & +1 & -1 & -1 & +1 & 380 & 304 & 30 \\
\hline 3 & +1 & +1 & -1 & +1 & -1 & +1 & -1 & 420 & 336 & 28 \\
\hline 4 & +1 & -1 & -1 & +1 & +1 & -1 & -1 & 395 & 316 & 27 \\
\hline 5 & +1 & +1 & +1 & -1 & +1 & -1 & -1 & 393 & 314 & 29 \\
\hline 6 & +1 & -1 & +1 & -1 & -1 & +1 & -1 & 383 & 306 & 29 \\
\hline 7 & +1 & +1 & -1 & -1 & -1 & -1 & +1 & 428 & 340 & 24 \\
\hline 8 & +1 & -1 & -1 & -1 & +1 & +1 & +1 & 320 & 320 & 26 \\
\hline
\end{tabular}


Based on the matrix of the complete factorial experiment, the coefficients of the regression equation are calculated (mathematical model).
Considering the function $\mathrm{Y}_{\mathrm{i}}$ as the analytical expression of the first order model, it is of the form:

$$
\begin{aligned}
& Y=c_{0} x_{0}+c_{1} x_{1}+c_{2} x_{2}+c_{3} x_{3}+c_{12} x_{1} x_{2}+c_{13} x_{1} x_{3}+c_{23} x_{2} x_{3} \\
& \mathrm{Y}_{1}=397.2+8.125 \cdot x_{1}-13.125 \cdot x_{2}-3.375 \cdot x_{3}-5.125 \cdot x_{1} \cdot x_{2}-1.375 \cdot x_{1} \cdot x_{3}-0.125 \cdot x_{2} \cdot x_{3} \\
& \mathrm{Y}_{2}=317.5+6.25 \cdot x_{1}-10.25 \cdot x_{2}-2.25 \cdot x_{3}-3.75 \cdot x_{1} \cdot x_{2}-0.75 \cdot x_{1} \cdot x_{3}-0.25 \cdot x_{2} \cdot x_{3} \\
& \mathrm{Y}_{3}=27.5-0.25 \cdot x_{1}+1.5 \cdot x_{2}+0.75 \cdot x_{3}+0 \cdot x_{1} \cdot x_{2}+0.25 \cdot x_{1} \cdot x_{3}-0.5 \cdot x_{2} \cdot x_{3}
\end{aligned}
$$

By replacing the coded variables xi with the relations (1) in the above equations and performing the related calculations, the following equations in natural quantities are obtained, equations that represent the mathematical model:

$$
\begin{aligned}
& \quad \mathrm{Y}_{1}\left(C_{E}, T_{f}, T_{\mathrm{w}}\right)=-1748.456+2799.3 \cdot C_{E}+1.515 \cdot T_{f}+2.102 \cdot T_{\hat{\mathrm{\imath}}}-17.08 \cdot C_{E} \cdot T_{f}- \\
& \quad 22.916 \cdot C_{E} \cdot T_{\hat{\mathrm{\imath}}}-0.000694 \cdot T_{f} \cdot T_{\mathrm{w}} \\
& \mathrm{Y}_{2}\left(C_{E}, T_{f}, T_{\mathrm{w}}\right)=-1595+19000 \cdot C_{E}+1,614 \cdot T_{f}+1.958 \cdot T_{w}-12.5 \cdot C_{E} \cdot T_{f}-12.5 \cdot C_{E} \\
& T_{\hat{\mathrm{\imath}}}-0.00138 \cdot T_{f} \cdot T_{\hat{\mathrm{I}}} \\
& \mathrm{Y}_{3}\left(C_{E}, T_{f}, T_{\mathrm{w}}\right)=-1272.9-2525 \cdot C_{E}+1.67 \cdot T_{f}+2.099 \cdot T_{\mathrm{w}}+4.16 \cdot C_{E} \cdot T_{\mathrm{w}}-0.0027 \cdot T_{f} \cdot \\
& T_{\mathrm{w}}
\end{aligned}
$$

The equations: (3), (4), (5) make up the mathematical model of the studied process valid for:

\begin{tabular}{|c|c|c|c|}
\hline \multirow{2}{*}{$\begin{array}{l}\text { Nr. } \\
\text { crt. }\end{array}$} & $\mathbf{Y}_{\text {2measured }}$ & $\mathbf{Y}_{\text {2calculated }}$ & $Y_{2 \text { meas }}-Y_{2 \text { calc }}$ \\
\hline & $\mathbf{R}_{\mathrm{p} 0,2}[\mathrm{MPa}]$ & $\mathbf{R}_{\mathrm{p} 0,2}[\mathrm{MPa}]$ & $\mathbf{R}_{\mathrm{p} 0,2}[\mathrm{MPa}]$ \\
\hline 1 & 306 & 308.996 & -2.996 \\
\hline 2 & 304 & 305.496 & -1.496 \\
\hline 3 & 336 & 337.332 & -1.332 \\
\hline 4 & 316 & 318.832 & -2.832 \\
\hline 5 & 314 & 315.404 & -1.404 \\
\hline 6 & 306 & 308.904 & -2.904 \\
\hline 7 & 340 & 342.747 & -2.747 \\
\hline 8 & 320 & 321.247 & -1.247 \\
\hline
\end{tabular}
$\mathrm{C}_{\mathrm{E}}=0.08-0.1 \%, \mathrm{~T}_{\mathrm{f}}=840 \ldots 900{ }^{\circ} \mathrm{C}$ and $\mathrm{T}_{\mathrm{w}}=$ $594 \ldots 606^{\circ} \mathrm{C}$.
Tables 1-3 show the measured values, those calculated using the mathematical model and the difference between the measured values and those calculated for the 3 mechanical properties studied.

Table 1. Measured, calculated and the difference between measured and calculated values for $R_{m}$

\begin{tabular}{|c|c|c|c|}
\hline \multirow{2}{*}{$\begin{array}{c}\text { Nr. } \\
\text { crt. }\end{array}$} & $\mathbf{Y}_{\text {1 measured }}$ & $\mathbf{Y}_{\text {1calculated }}$ & $\mathbf{Y}_{\text {1meas }}-\mathbf{Y}_{\text {1calc }}$ \\
\cline { 2 - 4 } & $\mathbf{R}_{\mathbf{m}}[\mathbf{M P a}]$ & $\mathbf{R}_{\mathbf{m}}[\mathbf{M P a}]$ & {$[\mathbf{M P a}]$} \\
\hline 1 & 382 & 384.098 & -2.098 \\
\hline 2 & 380 & 383.348 & -3.348 \\
\hline 3 & 420 & 410.93 & 9.07 \\
\hline 4 & 395 & 403.68 & -8.68 \\
\hline 5 & 393 & 383.869 & 9.131 \\
\hline 6 & 383 & 387.348 & -4.348 \\
\hline 7 & 428 & 419.201 & 8.799 \\
\hline 8 & 400 & 406.451 & -6.451 \\
\hline
\end{tabular}

Table 2. Measured, calculated and the difference between measured and calculated values for $R_{p 0,2}$ 
Table 3. Measured, calculated and the difference between measured and calculated values for $A_{5}$

\begin{tabular}{|c|c|c|c|}
\hline \multirow{2}{*}{$\begin{array}{c}\text { Nr. } \\
\text { crt. }\end{array}$} & $\mathbf{Y}_{\text {3measured }}$ & $\mathbf{Y}_{\text {3calculated }}$ & $\mathbf{Y}_{\text {3meas }}-\mathbf{Y}_{\text {3calc }}$ \\
\hline 1 & $\mathbf{A 5}[\mathbf{\%}]$ & $\mathbf{A 5}_{\mathbf{5}}[\mathbf{\%}]$ & $\mathbf{A 5}[\boldsymbol{\%}]$ \\
\hline 2 & 30 & 29.11 & -0.11 \\
\hline 3 & 28 & 29.190 & 0.81 \\
\hline 4 & 27 & 27.082 & 0.918 \\
\hline 5 & 29 & 28.09 & -0.162 \\
\hline 6 & 29 & 29.169 & 0.91 \\
\hline 7 & 24 & 24.118 & -0.169 \\
\hline 8 & 26 & 25.197 & -0.118 \\
\hline
\end{tabular}

Figures 1-6 show the variation of mechanical properties calculated with equations (3), (4), (5) depending on the values of the analysed factors, giving different values to the parameters of the studied process $\left(\mathrm{C}_{\mathrm{E}}, \mathrm{T}_{\mathrm{f}}, \mathrm{T}_{\mathrm{w}}\right)$.

Figure 1 shows the variation of the mechanical properties $R_{m}$ and $R_{p 0.2}$, for different values of the $C_{E}$ parameter, keeping constant, at the basic level, the values $\mathrm{T}_{\mathrm{f}}$ and $\mathrm{T}_{\mathrm{w}}$.

Figure 2 shows the variation of elongation at break $A_{5}$, for different values of the $C_{E}$ parameter, keeping constant, at the basic level, the values $T_{f}$ and $\mathrm{T}_{\mathrm{w}}$.

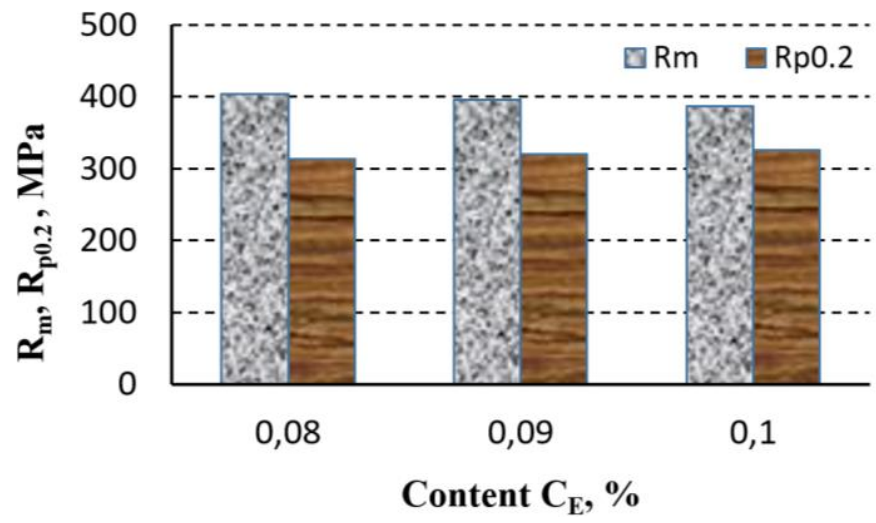

Fig. 1. $R_{m}=f\left(C_{E}\right)$ and $R_{p 0.2}=f(C E)$ for $T_{f}=c t$. and $T_{w}=c t$.

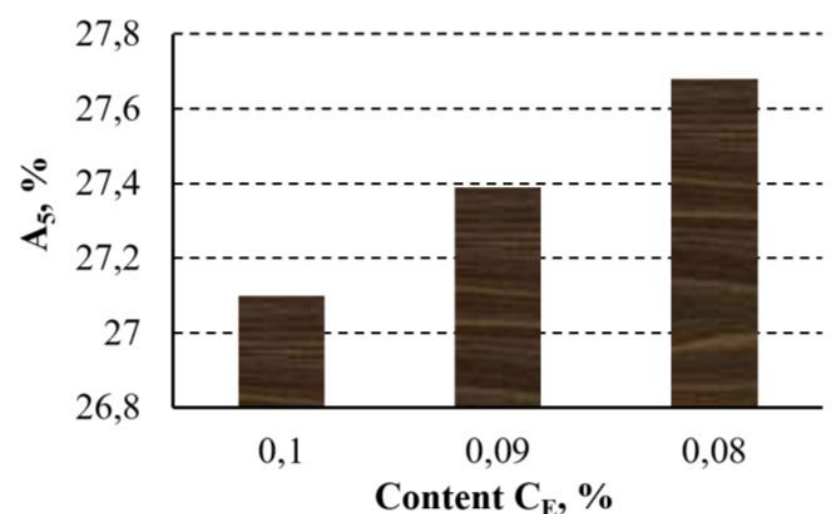

Fig. 2. $A_{5}=f\left(C_{E}\right)$ for $T_{f}=c t$. and $T_{w}=c t$.

Figure 3 shows the variation of the mechanical properties $R_{m}$ and $R_{p 0.2}$, for different values of the parameter $\mathrm{T}_{\mathrm{f}}$, keeping constant, at the basic level, the values $\mathrm{C}_{\mathrm{E}}$ and $\mathrm{T}_{\mathrm{w}}$. 


\section{THE ANNALS OF “DUNAREA DE JOS” UNIVERSITY OF GALATI \\ FASCICLE IX. METALLURGY AND MATERIALS SCIENCE \\ No. 2 - 2021, ISSN 2668-4748; e-ISSN 2668-4756 \\ Article DOI: $\underline{\text { https://doi.org/10.35219/mms.2021.2.01 }}$}

Figure 4 shows the variation of elongation at break $A_{5}$, for different values of the parameter $T_{f}$,

keeping constant, at the basic level, the values $\mathrm{C}_{\mathrm{E}}$ and $\mathrm{T}_{\mathrm{w}}$.

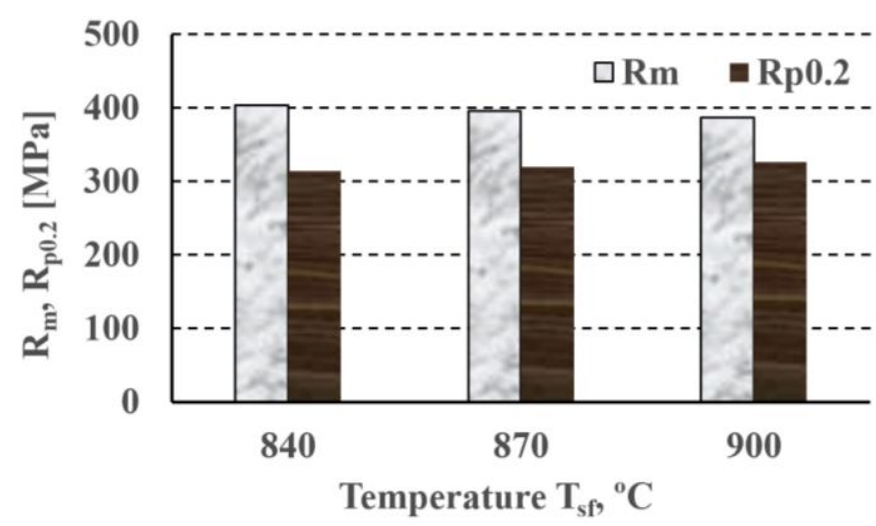

Fig. 3. $R_{m}=f\left(T_{f}\right)$ and $R_{p 0.2}=f\left(T_{f}\right)$ for $C_{E}=c t$. and $T_{w}=c t$.

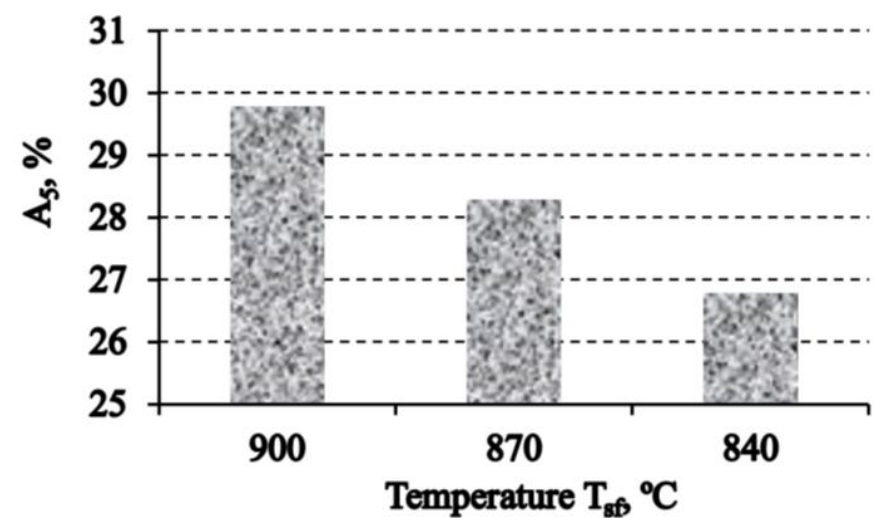

Fig. 4. $A_{5}=f\left(T_{f}\right)$ for $C_{E}=c t$. and $T_{w}=c t$.

Figure 5 shows the variation of the mechanical properties $R_{m}$ and $R_{p 0.2}$, for different values of the parameter $\mathrm{T}_{\mathrm{w}}$, keeping constant, at the basic level, the values $C_{E}$ and $T_{f}$.
Figure 6 shows the variation of elongation at break $\mathrm{A}_{5}$, for different values of the parameter $\mathrm{T}_{\mathrm{w}}$, keeping constant, at the basic level, the values $C_{E}$ and $\mathrm{T}_{\mathrm{f}}$.

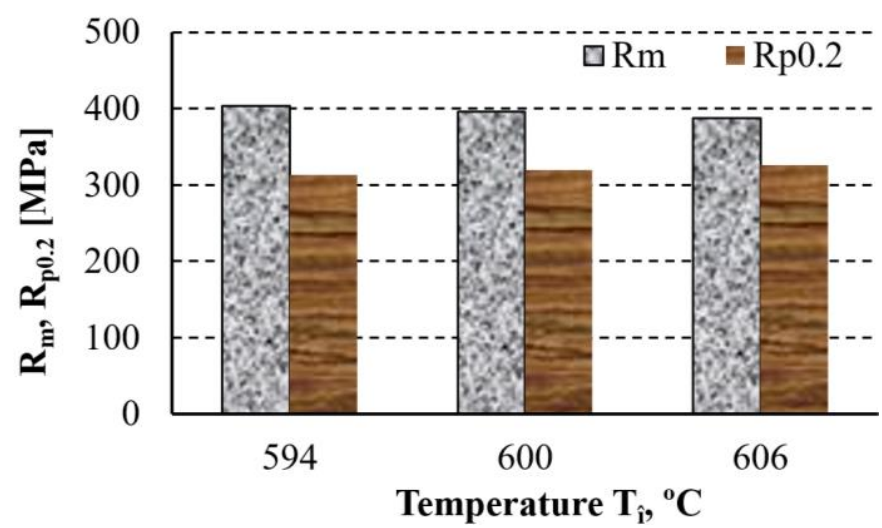

Fig. 5. $R_{m}=f\left(T_{w}\right)$ and $R_{p 0.2}=f\left(T_{w}\right)$ for $C_{E}=c t$. and $T_{f}=c t$. 


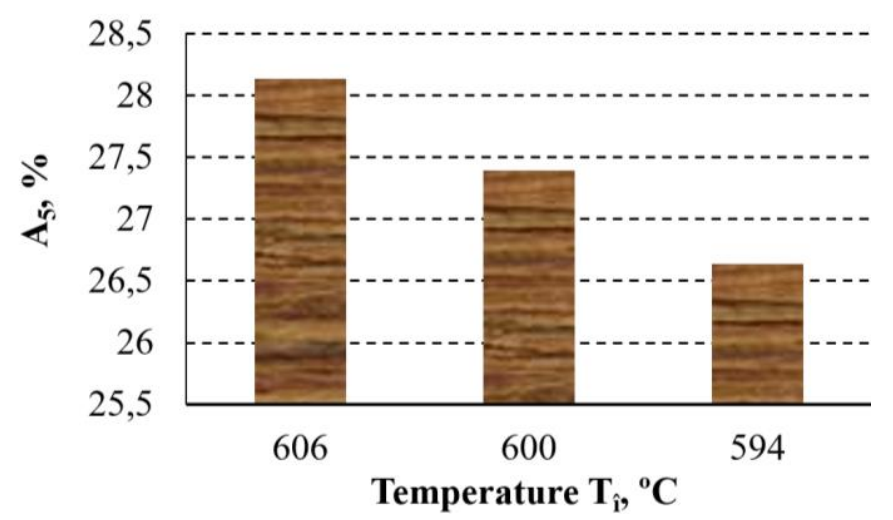

Fig. 6. $A_{5}=f\left(T_{f}\right)$ for $C_{E}=c t$. and $T_{w}=c t$.

As it can be seen, the calculated values, using the mathematical model, for the parameter to be optimized $\mathrm{Y}_{\mathrm{i}}(\mathrm{i}=1 \ldots 3)$ are very close to the measured values. Therefore, the mathematical model presented in the set of equations (3), (4), (5) allows the prediction of the properties for DD11 steel laminated to LBC from the Liberty Steel Galati plant. The prediction of the properties is achieved by varying the values of the technological parameters, within the experienced limits.

\section{Conclusions}

The elaborated mathematical model can be described as a function with three parameters, each studied mechanical property (output quantity) depends on:

- $\mathrm{C}_{\mathrm{E}}$ - carbon equivalent,

- $\mathrm{T}_{\mathrm{f}}$ - end rolling temperature,

- $\mathrm{T}_{\mathrm{w}}$ - temperature of the winding of the roller;

The differences between the values recorded when measuring the mechanical properties and those obtained by calculation based on the mathematical model developed, are small or very small.
The equations of the mathematical model, for the 3 studied mechanical properties, allow the prediction of the values of these properties by calculation, without the need of performing specific mechanical tests.

By using this mathematical model, time and money can be saved by those who apply it.

The elaborated mathematical model is in close accordance with the process of rolling hot strips.

\section{References}

[1]. Taloi D. Bratu C., Florian E., Berceanu E., Optimizarea proceselor metalurgice, E.D.P., Bucureşti 1983.

[2]. Taloi D., Optimizarea proceselor tehnologice-aplicaţii $\hat{\imath}$ metalurgie, Editura Academiei, Bucureşti, 1987.

[3]. Popescu D., Ionescu F., Dobrescu R., Stefanoiu D., Modelare in ingineria proceselor industriale, Editura AGIR Bucuresti, 2011.

[4]. Ciuca I., Dumitriu S., Modelarea si Optimizarea proceselor metalurgice de deformare plastica si tratamente termice, Ed. Didactica si Pedagogica, Bucuresti, 1998.

[5]. Baron T., et al., Statistică teoretică şi economică, Editura Didactică şi Pedagogică, Bucureşti, 1995.

[6]. Cazimirovici E., Bazele teoretice ale deformării plastice, Ed. Bren Bucureşti, 1999. 